\title{
Applying Soybean Oil to Dormant Peach Trees Thins Flower Buds
}

\author{
Renae E. Moran, Dennis E. Deyton ${ }^{1}$, Carl E. Sams, and \\ John C. Cummins \\ Department of Plant and Soil Sciences, The University of Tennessee, Knoxville, \\ TN 37901-1071
}

Additional index words. chemical thinner, dormant oil, fruit size, Prunus persica, flower bud hardiness

\begin{abstract}
Applications of soybean oil to dormant peach [Prunus persica (L.) Batsch] trees were tested for prebloom thinning of flower buds in five separate experiments. Data were combined from experiments in which $2.5 \%$ to $20 \%$ emulsified soybean oil was sprayed on 'Belle of Georgia' or 'Redhaven' trees. The number of dead flower buds was concentration-dependent with maximum bud kill of $53 \%$ occurring with application of $12 \%$ soybean oil. The amount of thinning was fairly consistent from year to year, ranging from $34 \%$ to $51 \%$ when $10 \%$ soybean oil was applied, but was less consistent when $5 \%$ was applied, ranging from $6 \%$ to $40 \%$. Overthinning by midwinter applications of soybean oil occurred in one experiment when bud mortality on nontreated trees was $40 \%$ due to natural causes. Mild to moderate spring freezes occurred in three experiments, but did not reduce yield more in soybean oil-thinned than in nontreated trees. Flower bud survival was improved when trees were sprayed with $10 \%$ or $12 \%$ soybean oil prior to a $-4{ }^{\circ} \mathrm{C}$ spring frost. Applications of soybean oil to dormant trees thinned flower buds, reduced the amount of hand thinning required, and hastened fruit maturity.
\end{abstract}

Overcropping of peaches results in undersized fruit, limb breakage, reduced tree cold hardiness, less return bloom, and delayed fruit maturity (Blanco et al., 1995; Byers and Marini, 1994; Dorsey and McMunn, 1928; Johnson and Handley, 1989; Tukey and Einset, 1939). Small fruit size results from competition for limited assimilates and depleted carbohydrate reserves (Grossman and DeJong, 1995). Reducing shoot growth and floral bud initiation limits return bloom (Byers et al., 1990). Crop load is managed commercially by manual fruit removal (thinning) to overcome these problems and to increase the economic value of the crop.

Hand thinning peach fruit is one of the most expensive production practices, but few alternatives to hand thinning are available. Mechanical thinning methods have been developed but result in uneven fruit spacing and require special equipment (Baugher et al., 1991; Glenn et al., 1994). Caustic bloom

Received for publication 5 Apr. 1999. Accepted for publication 2 Sept. 1999. We thank the United Soybean Board, the Tennessee Soybean Promotion Board, and the Tennessee Agriculture Experiment Station for providing financial support for this study. Mention of a trademark, proprietary product, or vendor does not constitute a guarantee or warranty of the product and does not imply its approval to the exclusion of other products or vendors that also may be suitable. The cost of publishing this paper was defrayed in part by the payment of page charges. Under postal regulations, this paper therefore must be hereby marked advertisement solely to indicate this fact.

${ }^{1}$ To whom reprint requests should be addressed. E-mail address: deytond@utk.edu thinners are inconsistent in effect and therefore not commercially acceptable (Byers and Lyons, 1985; Fallahi, 1997; Myers et al., 1993; Southwick et al., 1996), and many are not registered for commercial use. Alternatives that are inexpensive, safe, and consistent are still being sought. Soybean oil is exempted from normal Environmental Protection Agency (EPA) registration because it is a relatively nontoxic, common food constituent, not persistent in the environment, and has no significant adverse effects on the environment (U.S. Congress, 1996). Furthermore, it is relatively inexpensive. When applied to dormant peach trees, it thins flower buds in a concentrationdependent manner (Myers et al., 1996). However, how consistently it will thin fruit from year to year is not known.

The effects of thinning on fruit size and maturity decrease with time of application (Byers and Lyons, 1985; Havis, 1962; Weinberger, 1941). Petroleum oil applications to dormant peach trees can reduce crop load by killing flower buds before bloom (Call and Seeley, 1989; Deyton et al., 1992; Durner and Gianfagna, 1992), but little data are available on the thinning ability of soybean oil (Myers et al., 1996). However, a major concern of peach growers is thinning before the danger of frost is over. Soybean oil delays bloom of peach (Myers et al., 1996), but how it affects flower survival during a freeze is unknown. The objectives of this research were to determine: 1 ) if the thinning effect of soybean oil is consistent from year to year; 2) if it reduces or eliminates the need for hand thinning; and 3) how it affects flower bud cold hardiness, fruit quality, yield, and fruit maturity.
In all experiments, both a water control and soybean oil sprays were applied until runoff with a handgun. During application, neighboring trees were shielded with plastic tarpaulins. All trees were trained to the open-vase system, and spaced 4.3 to $4.5 \mathrm{~m}$ between trees and 5.5 $\mathrm{m}$ between rows. Crude soybean oil was used in Expt. 1 and degummed soybean oil (slightly refined to remove gums) was used in Expts. 25. Degummed soybean oil is more uniform and more stable in storage than is crude oil (personal communication with Central Soya, Fort Wayne, Ind.).

Expts. 1-3. The methods of Expts. 1-3 have been previously described (Myers et al., 1996) and will be summarized here. Soybean oil emulsified with Triton AG-44 or Latron AG-44 adjuvants (Rohm and Haas Co., Philadelphia) was applied in early February to dormant bearing trees (3- to 6-year-old) in concentrations from $2.5 \%$ to $20 \%$. Six, six, and four single-tree replications were used in Expts. 1, 2, and 3, respectively. Percentage of flower buds thinned was determined by counting the number of flower buds on 8 or 10 tagged shoots near the time of spraying and again $\approx 6$ weeks after spraying.

Expt. 4. In 1995, soybean oil was sprayed to runoff on 4-year-old 'Redhaven' trees on Lovell rootstock located at the Knoxville Experiment Station (KES) at the Univ. of Tennessee. Sprays of $0 \%$ (water control), $5 \%$, or $10 \%$ soybean oil were applied on $25 \mathrm{Feb}$. The adjuvant Latron B-1956 was premixed with soybean oil, prior to adding to spray water, at rates of $10 \%$ of the oil treatment. Flower buds were counted on 10 tagged shoots per tree on 23 Feb., and again on 28 Mar. (first open bloom), 1 month after treatment. Trees were harvested twice, the first time from 30 June to 7 July and the second time on 13 July. Total number of fruit per tree and fruit weight were recorded. The treatments were arranged in a randomized complete-block design with five single-tree replications.

Expt. 5. Sprays of 0\% (water control), 6\%, $8 \%, 10 \%$, or $12 \%$ soybean oil were applied on 30 Jan. 1997 to 6-year-old 'Redhaven' trees on 'Lovell' rootstock located at the KES. Latron B-1956 was premixed with soybean oil at a rate of $10 \%$ of the oil, before adding to the spray water. The study was a randomized complete-block design with seven replications for a total of 35 trees.

Oil residue was measured on four shoots per tree $1 \mathrm{~d}$ after application. Shoots were cut into $6-\mathrm{cm}$ sections and dipped in $10 \mathrm{~mL}$ of chloroform for $30 \mathrm{~s}$. This was repeated for a total of three times or $30 \mathrm{~mL}$. The chloroform and oil mixture was filtered through cheesecloth to remove debris and then was evaporated to dryness by passing a stream of air over the surface. The weight of control residues was used as an estimate of surface wax, and was subtracted from the oil and wax weights of the treatments to estimate the weight of oil residue. Data were expressed as oil residue per $\mathrm{cm}^{2}$ of shoot surface area, which was calculated by assuming the shoot was a cylinder and 
using the formula [surface area $=3.14$ (shoot diameter) (shoot length)].

Percentage of flowers thinned by soybean oil was measured as the number of flower buds on two or three shoots per tree on 7 Mar. (50\% open bloom of unsprayed trees), $37 \mathrm{~d}$ after application(DAFB). A freeze of $-4^{\circ} \mathrm{C}$ occurred 16 Mar. when trees were at petal fall. To determine the effects of oil on bud survival, two shoots per tree were cut on 16 Mar. and taken to the laboratory where they were kept in water and held at room temperature $\left(21^{\circ} \mathrm{C} \pm 1\right)$ for $1 \mathrm{~d}$. The flowers and flower buds were dissected to examine pistils for browning as an indication of cold damage. To determine the time required to hand-thin excessive fruit, the trees were hand thinned between 11 and 18 June to about one fruit per $15 \mathrm{~cm}$ of shoot length and the labor time was recorded. Fruit growth was measured by collecting five fruit per tree $37,43,53,62,76,98$, and 112 DAFB. The fruit were dried at $80{ }^{\circ} \mathrm{C}$ for 1 week and weighed. Trees were harvested the first time from 30 June (107 DAFB) to 2 July and then a second time from 10 to $11 \mathrm{July}$. All fruit were counted and weighed, and a random sample of 20 fruit per tree was collected for fruit quality analysis. Since fruit maturity varied with treatment, the samples were collected during the larger of the two harvests. Fruit samples were collected for $8 \%, 10 \%$, or $12 \%$ soybean oiltreated trees during the first harvest and for untreated trees and trees sprayed with $6 \%$ soybean oil during the second harvest. Fruit surface (exocarp) color was estimated using Clemson Color chips on five fruit per tree 112 DAFB. The same fruit (endocarp) were examined for split pit. Fruit firmness was measured by removing exocarp sections on two opposing sides of each fruit and puncturing the mesocarp with a FT 327 Effegi firmness tester (Effegi, Alfonsine, Italy) with a 7.9-mm tip. Fruit were ground in a food processor, the juice was filtered through Whatman \#1 paper, and soluble solids were measured with a handheld refractometer (Atago, Tokyo;0\% to 32\%).

Data for thinning were adjusted for bud death unrelated to soybean oil sprays. To determine the effects of soybean oil alone, percentage of bud loss of controls was subtracted from that of soybean oil-treated trees. Data from all five experiments were pooled for regression analysis with soybean oil concentration as the independent variable and bud death as the dependent variable. Statistical Analysis Systems software (SAS Inst., Cary, N.C.) was used to perform regressions and analysis of variance.

\section{Results}

Soybean oil residue that remained on dormant shoots after spraying in Expt. 5 increased asymptotically $(P \leq 0.05)$ with increasing soybean oil concentration (Fig. 1).

Soybean oil thinned fruit buds in all five experiments. Year-to-year variability occurred in the amount of bud thinning and was partially due to factors other than soybean oil, such as cold injury. In 1992, bud death on untreated trees was negligible so soybean oil resulted in bud loss $\geq 53 \%$. However, in 1993 at the KES, bud death was $42 \%$ on untreated trees, and bud loss with soybean oil thinning was as high as $92 \%$. Flower bud death due to the soybean oil alone was concentrationdependent (Fig. 2), and increased asymptotically with concentration. Spraying with $10 \%$ oil killed $34 \%$ to $51 \%$ of the buds in the five experiments. Leaf buds were not evaluated in the trials but soybean oil caused no apparent damage to them at these concentrations.

In 1997 , a mild freeze $\left(-4^{\circ} \mathrm{C}\right)$ occurred 16 Mar., when unsprayed trees in Expt. 5 were at petal fall and trees sprayed with $10 \%$ or $12 \%$ soybean oil had $\approx 80 \%$ to $90 \%$ flowers open or at petal fall. Although spraying $10 \%$ and $12 \%$ soybean oil killed $\approx 50 \%$ of the flower buds before bloom, the remaining buds were hardier than those from control trees (Fig. 3B). The survival of remaining buds increased significantly $(P \leq 0.05)$ with increasing soybean oil, and more than $95 \%$ of remaining flowers or flower buds survived the freeze. In contrast, only about $65 \%$ of flowers or flower buds on sampled shoots from unsprayed trees survived. Although frosts also occurred in the other trials, injury was not recorded after the frost.

In Expt. 5, the time required for follow-up hand thinning was significantly reduced $(P \leq$ $0.05)$ by soybean oil application (Fig. 3A). Soybean oil at $10 \%$ or $12 \%$ required little or no follow-up hand thinning, indicating that it can

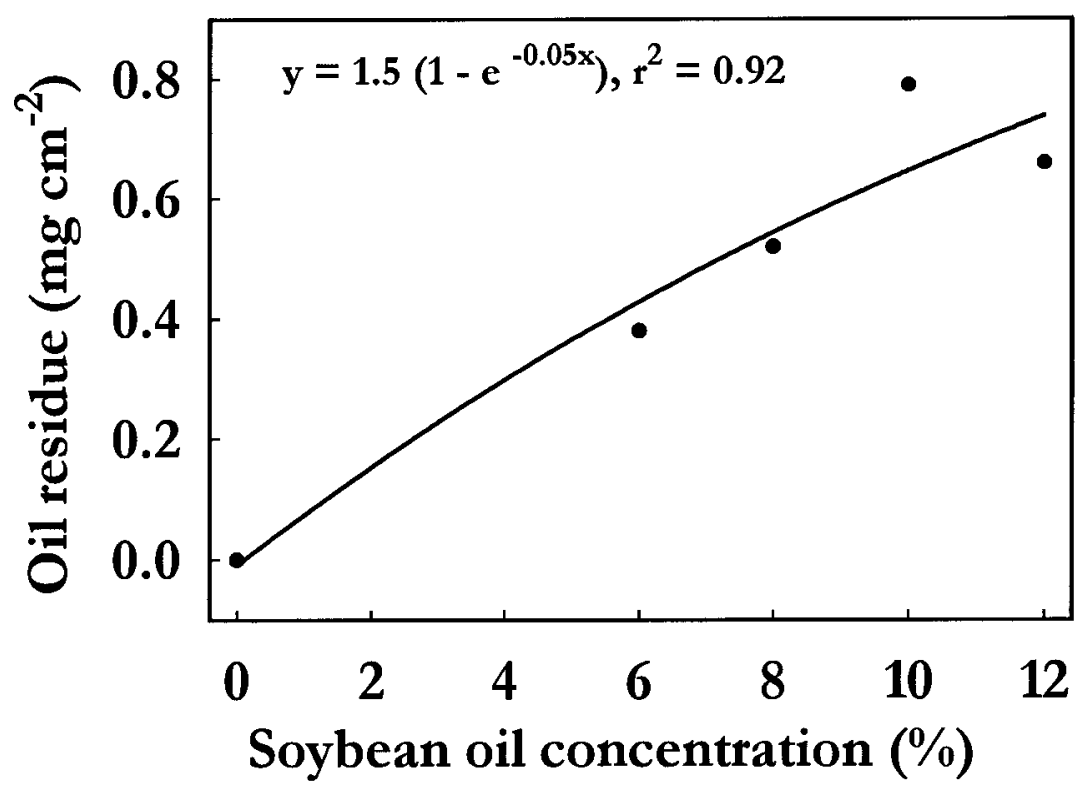

Fig. 1. The effect of soybean oil concentration on oil residue on 'Redhaven' peach shoots in 1997. Soybean oil residue was measured the day of application and is expressed on a shoot surface area basis. Each point is the mean of seven replicates.

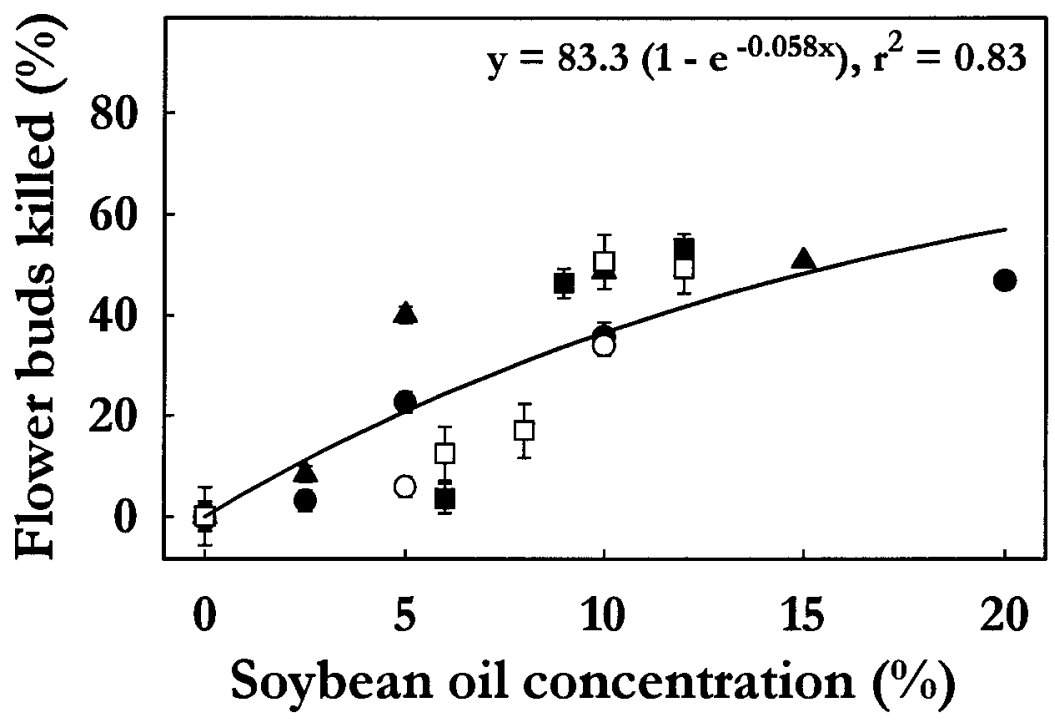

Fig. 2. The effect of soybean oil concentration on flower bud mortality due to soybean oil (number of dead buds on unsprayed trees subtracted out) in five experiments involving 'Belle of Georgia' trees in 1992 at Lenoir City (-); and 'Redhaven' trees at Middle Tennessee Experiment Station (ם) in 1993; and at Knoxville $(\boldsymbol{\Delta})$ in $1995(\bigcirc)$ and 1997 (口). Each point is the mean of four to seven replicates. 
eliminate the need for hand thinning in some instances. However, when a significant number of flower buds has been damaged by a previous freeze, spraying $10 \%$ or $12 \%$ oil may overthin the fruit.

In Expt. 5, fruits were hand-thinned in June primarily to determine the time required to thin. The untreated trees were hand-thinned later than is normal in commercial operations. Control (no thinning) or early hand-thinning treatments were not included in the trial. The additional fruit thinning by soybean oil resulted in a more intense yellow skin (Table 1), but did not affect flesh firmness or soluble solids (data not shown).

In Expt. 1, the crop was destroyed by a severe freeze at bloom $\left(-6^{\circ} \mathrm{C}\right.$ on $3 \mathrm{Apr}$.). Crop yield data from Expts. 2 and 3 have been published elsewhere (Myers et al., 1996). In Expt. 4 , a freeze at bloom $\left(-6{ }^{\circ} \mathrm{C}\right.$ on 23 Mar.) reduced yield, resulting in no difference between controls and treated trees (data not

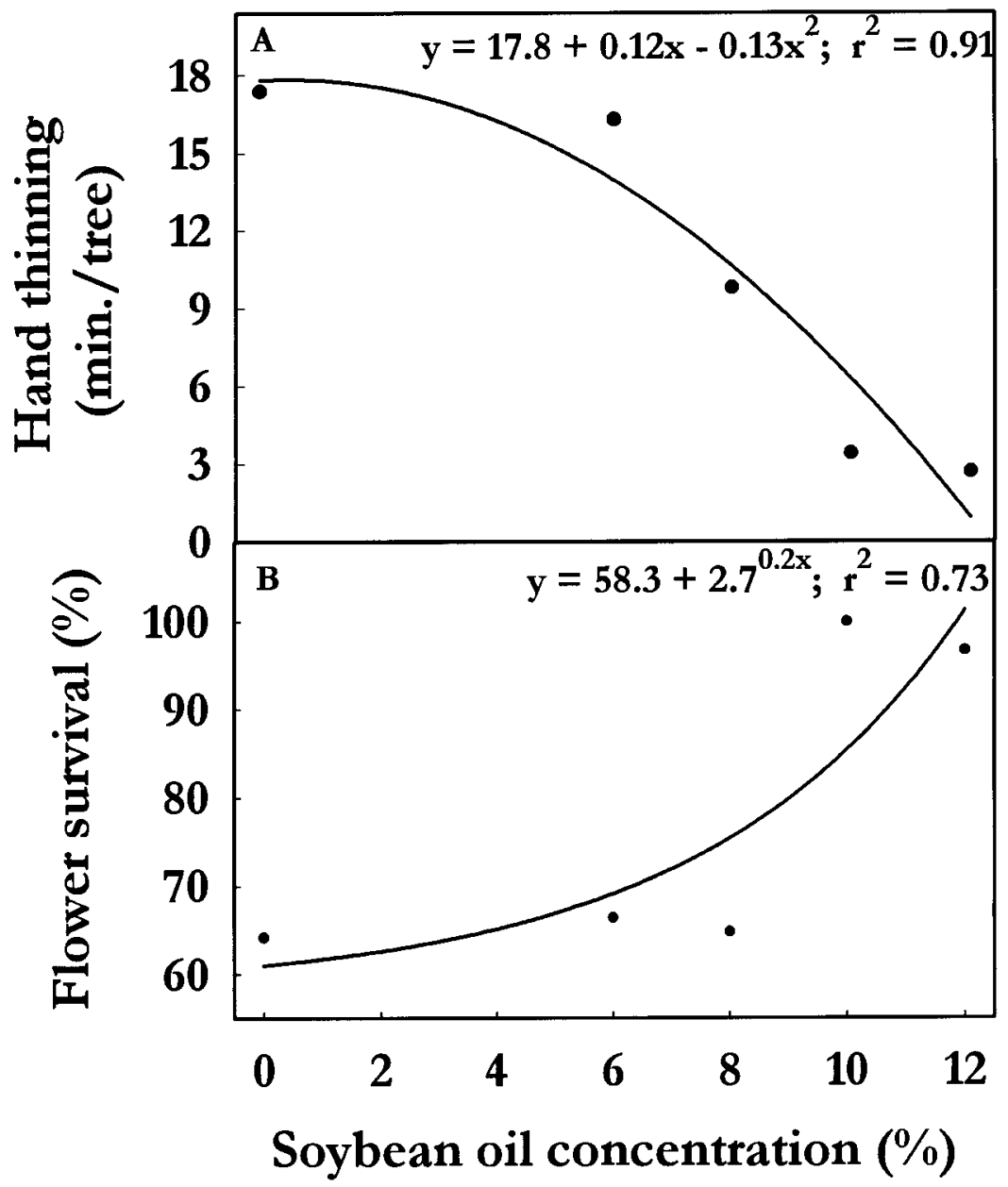

Fig. 3. The effect of soybean oil concentration on (A) time required for hand-thinning 'Redhaven' peaches and (B) flower survival of a freeze $\left(-4^{\circ} \mathrm{C}\right)$ on $16 \mathrm{Mar}$. 1997. Flower survival data were arcsin transformed for analysis, but the actual means are presented. Trees were hand-thinned to $\approx 1$ fruit per $15 \mathrm{~cm}$ of shoot length. Each value is the mean for seven replicates.

shown). In Expt. 5, the freeze during bloom $\left(-4^{\circ} \mathrm{C}\right)$ was not severe enough to limit yield or reduce flower density to below the desired level (Table 1). Total number of fruit, or the sum of both harvests, was significantly reduced by soybean oil. At harvest, control trees and those treated with $6 \%$ or $8 \%$ oil obviously had not been sufficiently hand-thinned. The trees had not been irrigated and were moisture-stressed, which also reduced fruit size.

Soybean oil application affected the proportion of fruit that was harvested early (Table 1). Trees sprayed with soybean oil had a greater proportion of fruit in the first harvest than did the control, and this increased linearly with increasing soybean oil concentration. The reverse occurred in the second harvest; control trees had a greater proportion of the total harvest in the second harvest than did trees treated with soybean oil.

In Expt. 5, mean fruit fresh weight increased linearly with increasing soybean oil concentration (Table 1). In this experiment, follow-up hand thinning was performed too late in the season to have an effect on fruit size, and control trees were overcropped.

The spraying of $10 \%$ and $12 \%$ soybean oil increased the incidence of split pit in Expt. 5 (Table 1). Overthinning can increase the occurrence of split pit (Childers et al., 1995), thus increased fruit thinning may have caused the increase in split pits. No fruit with split pits were found on trees sprayed with $6 \%$ or $8 \%$ soybean oil.

Fruit growth was measured periodically in Expt. 5 from 37 to 112 DAFB. Wintertime sprays of soybean oil increased mean fruit dry weight as early as $37 \mathrm{DAFB}(P \leq 0.01)$ and this trend continued till harvest (Fig. 4). Relative growth rate was not affected by fruit thinning (data not shown), but may have been measured too late in the season since the first measurement was 37 DAFB.

\section{Discussion}

Wintertime soybean oil applications reduced fruit number per tree and the need for follow-up hand thinning. The time required for hand thinning was reduced $40 \%$ to $80 \%$ by oil applications of $8 \%$ to $12 \%$. This reduction was similar to that obtained with other thinning agents, such as rope thinning (Baugher et

Table 1. Fruit quality, crop load, and fruit size of 'Redhaven' peach following dormant application of soybean oil in 1997.

\begin{tabular}{|c|c|c|c|c|c|c|c|}
\hline \multirow[b]{2}{*}{ Soybean oil (\%) } & \multirow[b]{2}{*}{ Fruit ground color ${ }^{\mathrm{z}}$} & \multicolumn{2}{|c|}{ Fruit yield $^{\mathrm{y}}$} & \multicolumn{2}{|c|}{ Yield distribution $^{\mathrm{x}}(\%)$} & \multirow[b]{2}{*}{ Fruit wt (g) } & \multirow[b]{2}{*}{ Split pits $(\%)$} \\
\hline & & No. tree & $\mathrm{kg} /$ tree & 1st harvest & 2nd harvest & & \\
\hline 0 & 2.9 & 1366 & 88 & 26 & 74 & 64 & 0 \\
\hline 6 & 4.5 & 1206 & 90 & 46 & 54 & 79 & 0 \\
\hline 8 & 3.9 & 1080 & 94 & 54 & 46 & 92 & 0 \\
\hline 10 & 4.4 & 646 & 67 & 69 & 31 & 112 & 17 \\
\hline 12 & 5.1 & 378 & 41 & 76 & 24 & 115 & 20 \\
\hline Linear trend & $* *$ & $* * *$ & $* * *$ & $* * *$ & $* * *$ & $* * *$ & $*$ \\
\hline Quadratic trend & NS & $* *$ & $* * *$ & NS & NS & NS & NS \\
\hline SE & 0.3 & 101 & 6 & 4.7 & 4.7 & 5 & 6 \\
\hline
\end{tabular}

${ }^{\mathrm{z}}$ Fruit ground color was rated on a scale of 1 to 6 , with 1 being green and 6 being yellow.

${ }^{y}$ Each value is a mean of seven replications. Fruit were hand-thinned from 11-18 June.

${ }^{x}$ Yield distribution and split pit data were arcsin transformed for analysis. Nontransformed means are presented.

Ns, *,**,**** Nonsignificant or significant at $P \leq 0.05,0.01$, or 0.001 , respectively. 


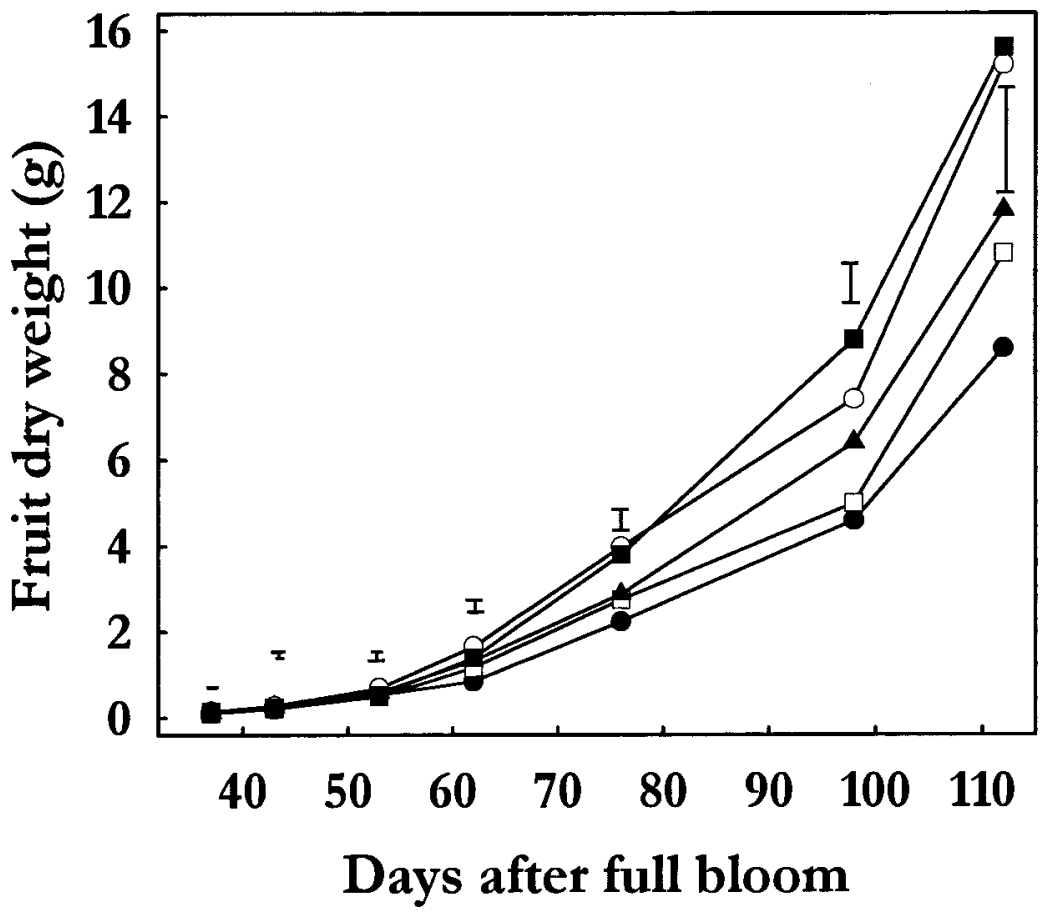

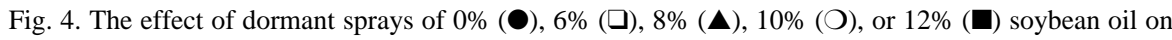
'Redhaven' peach fruit dry weight from 37 to $112 \mathrm{~d}$ after full bloom in 1997. Each point is the mean for seven replicates; bars represent $\mathrm{LSD}_{0.05}$.

al., 1988, 1991), gibberellin applications (Edgerton, 1966; Gur et al., 1993; Southwick et al., 1995), or caustic bloom thinners (Southwick et al., 1996). The advantages of soybean oil are similar to those for gibberellins (Edgerton, 1966; Gur et al., 1993; Southwick et al., 1996), which include a wide window of timing, bloom delay, minimal toxicity to mammals, no fruit phytotoxicity or fruit blemishes, low cost, and earlier fruit maturity. Bloom thinners, such as Armothin ${ }^{\circledR}$ $\{[N, N$-bis 2-(omega-hydroxpolyoxyethylene/ polyoxypropylene) ethyl alkylamine]; AKZONobel, Chicago (Southwick et al., 1998), have a narrow time in which they can be used, unlike soybean oil which can be applied during a period of several weeks. The earliest oil application date was $30 \mathrm{Jan}$. and the latest was $25 \mathrm{Feb}$., indicating a period of several weeks in which it may be effective, but we do not know if application time can be extended beyond these dates. Experiments are being conducted to determine this.

An important trait of thinning agents is year-to-year consistency in the amount of thinning that results. However, freezes at bloom made year-to-year crop load comparisons difficult, so in this study, evaluation of consistency was based on flower bud thinning. The amount of thinning was fairly consistent from year-to-year ( $34 \%$ to $51 \%$ ) when $10 \%$ soybean oil was applied, but was less consistent $(6 \%$ to $40 \%$ ) when $5 \%$ was applied. Thus, soybean oil shows promise as a reliable thinning agent. Soybean oil was not compared to petroleum oil in this trial, but conflicting reports exist as to the thinning ability of petroleum oil (Call and Seeley, 1989; Deyton et al., 1992; Myers et al., 1996). The extent of cultivar variability was not tested in this study, so our results are limited to the two cultivars that were tested.

An additional trait that is desired in thinning agents is an even distribution of fruit within the tree canopy. Clustering (close spacing) of fruit is undesirable since it can reduce fruit size and increase the incidence of disease (Southwick et al., 1995). Clustering was observed to be greatest in untreated trees and decreased with the degree of thinning. This suggests that soybean oil thins fairly evenly within shoots, as previously reported (Myers et al., 1996). Fruit distribution within the canopy did not appear to differ from the control.

Overthinning is another concern with the use of thinning agents, especially in the case of a spring freeze. Overthinning was partially dependent on the amount of bud kill due to factors other than the soybean oil. This was the case in years in which unexplained bud death was $>10 \%$ in control trees. Clearly, variability in bud death due to other causes such as cold injury should be considered when determining the concentration needed. Overthinning with soybean oil can be avoided by selecting a concentration based on bud kill at the time of application. When mild freezes occur, soybean oil may not result in greater losses, as indicated by the greater bud hardiness in Expt. 5. Dormant petroleum or soybean oil application retarded bloom and increased cold tolerance of peach in previous studies (Call and Seeley, 1989; Myers et al., 1996) and delayed bloom in this one, as well (data not shown). This may have resulted in the increase in freeze survival in trees with $10 \%$ and $12 \%$ soybean oil. At the time of the freeze, all flowers on control trees were open or at petal fall, while percentages of open flowers on trees sprayed with $6 \%$ or $8 \%, 10 \%$, and $12 \%$ oil were $97 \%, 87 \%$, and $92 \%$, respectively. When trees were sprayed with $6 \%$ or $8 \%$ oil, there was no increase in flower survival, possibly due to insufficient bloom delay in these treatments.

The effects of soybean oil on fruit quality were similar to the effect of bloom thinning. Bloom thinning increases fruit size, hastens maturity, and increases shoot growth compared with thinning after bloom (Glenn et al., 1994; Grossman and DeJong, 1995; Tukey and Einset, 1939; Weinberger, 1941). Fruit size in Expt. 5 was greater with soybean oil treatments than with hand thinning, but this effect may have been greater than would normally occur because of late hand thinning and overcropping of control trees. Reducing interfruit competition at bloom increases the supply of assimilates for the remaining fruit at an earlier time in their development (Grossman and DeJong, 1995). This effect on fruit size was evident as early as 37 DAFB when fruit dry weight was greater in soybean oil-thinned trees. Thinning before bloom with soybean oil caused a greater increase in size because thinning was earlier. Although the number of fruit was reduced by $8 \%$ soybean oil, the increase in fruit size compensated for the reduction in the number of fruit, as indicated by the lack of reduction in total yield/tree with this treatment. In addition to the effects on fruit size, soybean oil also hastened maturity, as do other bloom thinning methods (Havis, 1962; Tukey and Einset, 1939; Weinberger, 1941). Thinning with soybean oil hastened maturity in 1997. In the first harvest, $26 \%$ of the total crop on control trees was harvested, but $46 \%$ to $76 \%$ was harvested from soybean oil-thinned trees. However, the effect on maturity cannot be entirely attributed to the earliness of thinning, since crop load at harvest differed for control vs. soybean oil-thinned trees. Disorders common to other thinning methods may also occur with soybean oil thinning, since split pits occurred more frequently in trees that were heavily thinned in Expt. 5. Soybean oil caused no fruit marks or blemishes.

Thinning peach trees with soybean oil during dormancy was consistent from year to year. However, concentrations of $\geq 10 \%$ caused overthinning in years when bud death prior to application was $>10 \%$. Spring freezes did increase losses in trees thinned with soybean oil vs. control trees, and spring freeze survival was increased by soybean oil application. Dormant applications of soybean oil may allow growers in areas that are prone to spring freezes (i.e., southeastern United States) to take advantage of prebloom thinning and significantly reduce the costs of hand thinning.

\section{Literature Cited}

Baugher, T.A., K.C.Elliot, D.W.Leach, B.D. Horton, and S.S. Miller. 1991. Improved methods of mechanically thinning peaches at full bloom. J. Amer. Soc. Hort. Sci. 116:766-769.

Baugher, T.A., K.C. Elliot, S.H. Blizzard, S.I. Walter, and T.A. Keiser. 1988. Mechanical bloom thinning of peach. HortScience 23:981-983.

Blanco, A., A. Pequerul, J. Val, E. Monge, and J. 
Gomez Aparisi. 1995. Crop-load effects on vegetative growth, mineral nutrient concentration and leaf water potential in 'Catherine' peach. J. Hort. Sci. 70:623-629.

Byers, R.E., D.H. Carbaugh, and C.N. Presley. 1990 The influence of bloom thinning and $\mathrm{GA}_{3}$ sprays on flower bud numbers and distribution in peach trees. J. Hort. Sci. 65:143-150.

Byers, R.E. and C.G. Lyons. 1985. Peach flower thinning and possible sites of action of desiccating chemicals. J. Amer. Soc. Hort. Sci. 110:662667.

Byers, R.E. and R.P. Marini. 1994. Influence of blossom and fruit thinning on peach flower bud tolerance to an early spring freeze. HortScience 29:146-148.

Call, R.E. and S.D. Seeley. 1989. Flower bud coatings of spray oils delay dehardening and bloom in peach trees. HortScience 24:914-915.

Childers, N.F., J.R. Morris, and G.S. Sibbett. 1995. Modern fruit science. 10th ed. Horticultural Publications. Gainesville, Fla.

Deyton, D.E., C.E. Sams, and J.C. Cummins. 1992. Application of dormant oil to peach trees modifies bud-twig internal atmosphere. HortScience 27:1304-1305.

Dorsey, M.J. and R.L. McMunn. 1928. Relation of the time of thinning peaches to the growth of fruit and tree. Proc. Amer. Soc. Hort. Sci. 24:221-228.

Durner, E.F. and T.J. Gianfagna. 1992. Interactions of ethephon, whitewashing, and dormant oil on peach pistil growth, hardiness, and yield. HortScience 27:104-105.

Edgerton, L.J. 1966. Some effects of gibberellin and growth retardants on bud development and cold hardiness of peach. Proc. Amer. Soc. Hort. Sci. 88:197-203

Fallahi, E. 1997. Applications of endothalic acid, pelargonic acid, and hydrogen cyanamide for blossom thinning in apple and peach. HortTechnology 7:395-399.

Glenn, D.M., D.L. Peterson, D. Giovannini, and M. Faust. 1994. Mechanical thinning of peaches is effective postbloom. HortScience 29:850-853.

Grossman, Y.L. and T.M. DeJong. 1995. Maximum fruit growth potential and seasonal patterns of resource dynamics during peach growth. Ann. Bot. 75:553-560.

Gur, A., E. Harcabi, and A. Breuer-Mizrahi. 1993. Control of peach flowering with gibberellins. Acta Hort. 329:183-186.

Havis, A.L. 1962. Effects of time of fruit thinning of Redhaven peach. Proc. Amer. Soc. Hort. Sci. 80:172-176.

Johnson, R.S. and D.F. Handley. 1989. Thinning response of early, mid-, and late-season peaches. J. Amer. Soc. Hort. Sci. 114:852-855.

Myers, R.E., D.E. Deyton, and C.E. Sams. 1996 Applying soybean oil to dormant peach trees alters internal atmosphere, reduces respiration, delays bloom, and thins flower buds. J. Amer. Soc. Hort. Sci. 121:96-100.
Myers, S.C., A. King, and A.T. Savelle. 1993. Bloom thinning of 'Winblo' peach and 'Fantasia' nectarine with monocarbamide dihydrogensulfate. HortScience 28:616-617.

Southwick, S.M., K.G. Weis, and J.T. Yeager. 1996. Bloom thinning 'Loadel' cling peach with a surfactant. J. Amer. Soc. Hort. Sci. 121:334-338.

Southwick, S.M., K.G. Weis, J.T. Yeager, J.K. Hasey, and M.E. Rupert. 1998. Bloom thinning of 'Loadel' cling peach with a surfactant: Effects of concentration, carrier volume, and differential applications within the canopy. HortTechnology 8:55-58.

Southwick, S.M., K.G. Weis, J.T. Yeager, and H. Zhou. 1995. Controlling cropping in 'Loadel' cling peach using gibberellin: Effects on flower density, fruit distribution, fruit firmness, fruit thinning, and yield. J. Amer. Soc. Hort. Sci. 120:1087-1095.

Tukey, H.B. and O. Einset. 1939. Effect of fruit thinning on size, color, and yield of peaches and on growth and blossoming of the tree. Proc. Amer. Soc. Hort. Sci. 36:314-319.

U.S. Congress. 1996. Exemption of certain pesticide substances from federal insecticide, fungicide, and rodenticide act requirements. Federal Registry (40 CFR Part 152). U.S. Govt. Printing Office, Washington, D.C., 6 Mar. 1996.

Weinberger, J.H. 1941. Studies on time of peach thinning from blossoming to maturity. Proc. Amer. Soc. Hort. Sci. 38:137-140 